\title{
The receptor for advanced glycation end products and its ligands: a new inflammatory pathway in lung disease?
}

\author{
Patrizia Morbini ${ }^{1}$, Chiara Villa ${ }^{1}$, Ilaria Campo ${ }^{2}$, Michele Zorzetto $^{2}$, Simona Inghilleri $^{3}$ and \\ Maurizio Luisetti ${ }^{2}$ \\ ${ }^{1}$ Dipartimento di Anatomia ed Istologia Patologica, IRCCS Policlinico San Matteo, Università di Pavia, Pavia, \\ Italy; ${ }^{2}$ Laborarorio di Biochimica \& Genetica, Clinica Malattie Apparato Respiratorio, IRCCS Policlinico San \\ Matteo, Università di Pavia, Pavia, Italy and ${ }^{3}$ Clinica Malattie Apparato Respiratorio, IRCCS Policlinico San \\ Matteo, Università di Pavia, Pavia, Italy
}

\begin{abstract}
The binding of the receptor for advanced glycation end products (RAGE) with its ligands begins a sustained period of cellular activation and inflammatory signal amplification in different tissues and diseases. This binding could represent an as yet uninvestigated pathway of inflammatory reaction in the lung, where the presence of the receptor has been largely documented and advanced glycation end products (AGEs) are produced by nonenzymatic glycation and oxidation of proteins and lipids, driven by smoke and pollutants exposure or inflammatory stress. We immunohistochemically assessed the expression of RAGE and of its major proinflammatory ligands, $\mathrm{N}$-e-carboxy-methyl-lysine, S100B and S-100A12 in normal lung and in nonneoplastic lung disorders including smoke-related airway disease, granulomatous inflammation, postobstructive damage and usual interstitial pneumonia. In normal lung low expression of the receptor was observed in bronchiolar epithelia, type II pneumocytes, macrophages and some endothelia. S100A12 and S100B were expressed, respectively, in granulocytes and in dendritic cells. Carboxy-methyl-lysine was present in bronchiolar epithelia and macrophages. In all pathological conditions associated with inflammation and lung damage overexpression of both the receptor and of AGEs was observed in bronchiolar epithelia, type II alveolar pneumocytes, alveolar macrophages and endothelia. RAGE overexpression was more evident in epithelia associated with inflammatory cell aggregates. Fibroblasts in usual interstitial pneumonia expressed both the receptor and AGEs. The number of S100A12 and S100B immunoreactive inflammatory cells was variable. S100A12 was also expressed in mononuclear inflammatory cells and in activated epithelia. The activation of the inflammatory pathway controlled by the RAGE is not specific of a single lung disease, however, it may be relevant as a nonspecific pathway of sustained inflammation in lung tissue, and on this basis therapeutic approaches based on receptor blockage can be envisaged.
\end{abstract}

Modern Pathology (2006) 19, 1437-1445. doi:10.1038/modpathol.3800661; published online 25 August 2006

Keywords: RAGE; AGE; s100-calgranulin; lung inflammation

The receptor for advanced glycation end products (RAGE) is a multiligand membrane receptor able to engage classes of unrelated molecules, recognizing their tertiary structures rather than amino-acid sequences. $^{1,2}$ Major ligands of RAGE comprise heterogeneous groups of molecules, such as advanced glycation end products (AGEs), proinflammatory cytokine-like mediators of the S100/

Correspondence: Dr P Morbini, MD, PhD, Istituto di Anatomia Patologica, IRCCS Policlinico San Matteo, Università di Pavia, Via Forlanini 16, Pavia 27100, Italy.

E-mail p.morbini@smatteo.pv.it

Received 21 February 2006; revised and accepted 15 June 2006; published online 25 August 2006 calgranulin family (S100A12 and S100B), amphoterin and $\beta$-sheet fibrils of amyloid. While the interaction of RAGE with the last two molecules seems to be involved in rather specific processes, namely neurite outgrowth and tumor cell invasion and migration, ${ }^{1}$ and neuronal activation and apoptosis in Alzheimer disease, RAGE binding with AGEs and S100/calgranulins has been involved in a rapidly expanding series of inflammatory conditions associated with diabetes, ${ }^{3}$ atherosclerosis ${ }^{2,4}$ and rheumatological disorders. ${ }^{5,6}$ Ligand binding to RAGE does not accelerate their clearance or degradation but rather begins a sustained period of cellular activation mediated by receptor-dependent signaling and RAGE overepression. Proinflamma- 
tory RAGE ligands comprise several families of unrelated molecules: AGEs are a heterogeneous group of compounds deriving from the nonenzymatic glycation and oxidation of proteins and lipids; their formation in several pathophysiologic situations associated with inflammation is triggered by oxidant stress. ${ }^{7}$ The S100/calgranulins are a family of closely related calcium-binding polypeptides, which have been implicated in the regulation of protein phosphorylation, $\mathrm{Ca}^{2+}$ homeostasis, enzyme and transcription factor activities, cell growth and differentiation and in the inflammatory response. ${ }^{8}$ S100A12 and S100-B have been shown to activate endothelia, vascular smooth muscle cells, monocytes and $\mathrm{T}$ cells via RAGE, resulting in the generation of cytokines and proinflammatory adhesion molecules. ${ }^{2,5}$ Moreover, S100A12-calgranulin is expressed in polymorphonuclear granulocytes and is present in the serum in a wide range of inflammatory diseases. ${ }^{9-11}$

RAGE is expressed at low levels in normal tissues and in the vessels and becomes upregulated at sites where its ligands accumulate. ${ }^{1,2}$ RAGE was initially extracted and sequenced from bovine lung. ${ }^{12,13}$ Subsequent immunohistochemical and hybridization studies confirmed its presence in bovine, rat and human lung. ${ }^{14-16}$ Recently, an extensive immunohistochemical survey of normal human tissues showed RAGE expression in type II alveolar pneumocytes, endothelia and alveolar macrophages. ${ }^{17}$

On the basis of these data, we speculated that RAGE-ligand interaction could represent an as yet uninvestigated pathway of inflammatory reaction in the lung. In particular, lungs are sites of intense oxidative activity by reactive oxygen intermediates both in airways, as a consequence of smoke and pollutant exposure, ${ }^{18,19}$ and in peripheral parenchyma, as a result of inflammatory stress..$^{20,21} \mathrm{We}$ aimed, with the present study, at investigating the activation of this inflammatory pathway in lung pathology by assessing the pattern of expression of RAGE and of its major proinflammatory ligands, $N$ - $\varepsilon$-carboxy-methyl-lysine, S100B and S-100A12 in normal lung and in several common non-neoplastic lung disorders.

\section{Materials and methods}

\section{Case Series}

Lung samples obtained at video-assisted thoracoscopy performed for the diagnosis of interstitial lung diseases, and samples of non-neoplastic tissue obtained from lobectomies performed in patients with lung cancer were used for the study.

Samples obtained at video-assisted thoracoscopy included 10 usual interstitial pneumonias, five organizing pneumonias, seven sarcoidosis, three Langerhans cell histiocytosis and two tuberculosis. Non-neoplastic samples from lobectomies included six histologically normal samples from nonsmokers,
15 samples with histological evidence of smokeinduced lesions (chronic bronchiolitis, peribronchiolar fibrosis, pigmented macrophages, emphysema) from smokers, seven of whom had also clinical evidence of chronic obstructive pulmonary disease and six samples showing nonspecific inflammation associated with proximal neoplastic airway obstruction. All cases were reviewed to confirm the original diagnosis according to more recent classification criteria. ${ }^{22}$

\section{Immunohistochemistry}

Sections of formalin-fixed, paraffin-embedded samples were incubated with a goat antibody specific for amino acids 42-59 of the extracellular domain of RAGE (V-type domain) (Abcam, Cambridge, UK), and with antibodies against RAGE ligands: $N-\varepsilon$-(carboxymethyl)-lysine, one of the major components of AGEs (TransGenic Inc., Kumamoto, Japan), S100B (DakoCytomation, Carpinteria, CA, USA), and S-100 A12 (Santa Cruz Biotechnologies, Santa Cruz, CA, USA). Working dilutions were 1:4000 for RAGE and S-100A12 and 1:1000 for carboxy-methyl-lysine and S100B. Microwave oven pretreatment in pH6 citrate buffer was required for s100B immunoreactions. The reactions were revealed using peroxidase-conjugated avidinbiotin complex (LSAB-plus kit, DakoCytomation) and diaminobenzidine tetrahydrocloride as chromogen substrate (DakoCytomation). Each reaction set included a negative control obtained with substitution of the primary antibody with dilution buffer. Immunohistochemical reactions were evaluated by a pathologist, who recorded the presence of immune reactivity and the cell types expressing each antigen. The intensity of expression in any given cell type (or extracellular fluid) was semiquantitatively assessed as low or high as a function of the degree of brown diaminobenzidine stain. Overall, all cells of a given type showed a similar degree of immunoreactivity.

\section{Results}

The results detailed in the following paragraphs are summarized in Table 1.

\section{Normal Lung}

In normal lung (Figure 1a, c, e), low to intermediate RAGE immunoreactivity was observed in bronchiolar epithelia, type II alveolar pneumocytes and alveolar macrophages; large-sized vessel endothelia were also faintly stained. S100A12 and S100B were expressed, respectively, in sparse, mainly intravascular, polymorphonuclear granulocytes, and in rare interstitial dendritic cells, mainly in subepithelial location. Peribronchial nerves were also immunoreactive for S100B. Carboxy-methyl-lysine localiza- 
Table 1 Distribution of immunoreactivity and intensity of staining in different cell types in normal lung and common non-neoplastic lung disorders

\begin{tabular}{|c|c|c|c|c|}
\hline & $R A G E$ & Carboxy-methyl-lysine & S100A12 & $S 100 B$ \\
\hline Normal lung & $\begin{array}{l}\text { Bronchiolar epithelia } \\
\text { (L) } \\
\text { Type } 2 \text { pneumocytes } \\
\text { (L) } \\
\text { Macrophages (L) } \\
\text { Endothelia (L) }\end{array}$ & $\begin{array}{l}\text { Bronchiolar epithelia } \\
\text { (L) } \\
\text { Macrophages (L) }\end{array}$ & $\begin{array}{l}\text { Polymorphonuclear } \\
\text { granulocytes }(\mathrm{H})\end{array}$ & $\begin{array}{l}\text { Interstitial dendritic } \\
\text { cells (H) } \\
\text { Peribronchial nerves } \\
\text { (H) }\end{array}$ \\
\hline Smoke-related damage & $\begin{array}{l}\text { Bronchiolar epithelia } \\
\text { (H) } \\
\text { Reactive pneumocytes } \\
\text { (H) } \\
\text { Pneumocytes } \\
\text { associated with } \\
\text { inflammatory } \\
\text { infiltrates (H) } \\
\text { Macrophages (H) } \\
\text { Endothelia (L) } \\
\text { Extracellular fluid (L) }\end{array}$ & $\begin{array}{l}\text { Bronchiolar epithelia } \\
\text { (H) } \\
\text { Reactive pneumocytes } \\
\text { (H) } \\
\text { Pneumocytes } \\
\text { associated with } \\
\text { inflammatory } \\
\text { infiltrates (L) } \\
\text { Macrophages (H) } \\
\text { Endothelia (L) } \\
\text { Extracellular fluid (L) }\end{array}$ & $\begin{array}{l}\text { Polymorphonuclear } \\
\text { granulocytes (H) } \\
\text { Extracellular fluid (L) } \\
\text { Bronchiolar epithelia } \\
\text { (L) } \\
\text { Macrophages (L) }\end{array}$ & $\begin{array}{l}\text { Airway dendritic cells } \\
\text { (H) }\end{array}$ \\
\hline $\begin{array}{l}\text { Postobstructive } \\
\text { pneumonia }\end{array}$ & $\begin{array}{l}\text { Reactive pneumocytes } \\
\text { (H) } \\
\text { Pneumocytes } \\
\text { associated with } \\
\text { inflammatory } \\
\text { infiltrates (H) } \\
\text { Macrophages (H) } \\
\text { Endothelia (L) } \\
\text { Fibroblasts (L) } \\
\text { Extracellular fluid (L) }\end{array}$ & $\begin{array}{l}\text { Reactive pneumocytes } \\
\text { (L) } \\
\text { Pneumocytes } \\
\text { associated with } \\
\text { inflammatory } \\
\text { infiltrates (L) } \\
\text { Macrophages (H) } \\
\text { Endothelia (L) } \\
\text { Fibroblasts (L) } \\
\text { Extracellular fluid (L) }\end{array}$ & $\begin{array}{l}\text { Polymorphonuclear } \\
\text { granulocytes (H) } \\
\text { Extracellular fluid (L) } \\
\text { Bronchiolar epithelia } \\
\text { (L) } \\
\text { Macrophages (L) }\end{array}$ & $\begin{array}{l}\text { Interstitial dendritic } \\
\text { cells }(\mathrm{H})\end{array}$ \\
\hline Organizing pneumonia & $\begin{array}{l}\text { Reactive pneumocytes } \\
\text { (H) } \\
\text { Bronchiolar epithelia } \\
\text { (H) } \\
\text { Macrophages (H) } \\
\text { Endothelia (H) } \\
\text { Fibroblasts (L) } \\
\text { Extracellular fluid (L) }\end{array}$ & $\begin{array}{l}\text { Reactive pneumocytes } \\
\text { (L) } \\
\text { Bronchiolar epithelia } \\
\text { (L) } \\
\text { Macrophages (H) } \\
\text { Endothelia (H) } \\
\text { Fibroblasts (L) } \\
\text { Extracellular fluid (L) }\end{array}$ & $\begin{array}{l}\text { Polymorphonuclear } \\
\text { granulocytes (H) } \\
\text { Extracellular fluid (L) } \\
\text { Reactive pneumocytes } \\
\text { (L) } \\
\text { Macrophages (L) }\end{array}$ & $\begin{array}{l}\text { Interstitial dendritic } \\
\text { cells }(\mathrm{H})\end{array}$ \\
\hline $\begin{array}{l}\text { Granulomatous } \\
\text { disease }\end{array}$ & $\begin{array}{l}\text { Epithelioid and giant } \\
\text { cells }(\mathrm{H}) \\
\text { Reactive pneumocytes } \\
\text { (H) }\end{array}$ & $\begin{array}{l}\text { Epithelioid and giant } \\
\text { cells }(\mathrm{H}) \\
\text { Reactive pneumocytes } \\
\text { (H) }\end{array}$ & $\begin{array}{l}\text { Epithelioid and giant } \\
\text { cells }(\mathrm{H})\end{array}$ & $\begin{array}{l}\text { Interstitial dendritic } \\
\text { cells }(\mathrm{H})\end{array}$ \\
\hline $\begin{array}{l}\text { Usual interstitial } \\
\text { pneumonia }\end{array}$ & $\begin{array}{l}\text { Reactive pneumocytes } \\
\text { (H) } \\
\text { Alveolar } \\
\text { bronchiolization (H) } \\
\text { Endothelia (H) } \\
\text { Extracellular fluid (L) } \\
\text { Fibroblasts (H) }\end{array}$ & $\begin{array}{l}\text { Reactive pneumocytes } \\
\text { (H) } \\
\text { Alveolar } \\
\text { bronchiolization (H) } \\
\text { Endothelia (H) } \\
\text { Extracellular fluid (L) } \\
\text { Fibroblasts (H) }\end{array}$ & $\begin{array}{l}\text { Polymorphonuclear } \\
\text { granulocytes (H) } \\
\text { Reactive pneumocytes } \\
\text { (H) } \\
\text { Endothelia (L) } \\
\text { Macrophages (L) } \\
\text { Extracellular fluid (L) }\end{array}$ & $\begin{array}{l}\text { Interstitial dendritic } \\
\text { cells }(\mathrm{H})\end{array}$ \\
\hline
\end{tabular}

H: high degree of immunoreactivity; L: low degree of immunoreactivity.

tion was similar to that of RAGE in bronchiolar epithelia and macrophages; it was only slightly expressed in type II pneumocytes; endothelia were negative. Intravascular serum was occasionally reactive for RAGE, carboxy-methyl-lysine and S100A12.

\section{Smoke-Related Pulmonary Disease}

Lungs with lesions related to smoking (Figure 1b, d, $\mathrm{f}, \mathrm{h}$ ) showed extensive RAGE reactivity in bronchiolar epithelia and in areas of alveolar bronchiolization, as well as in reactive pneumocytes. Epithelial cells closely related to inflammatory infiltrates were strongly immunoreactive for RAGE (Figure 2a). Alveolar macrophages and endothelia were also positive. S100A12 was observed in polymorphonuclear granulocytes and in extracellular fluid. Low reactivity was present in bronchiolar epithelia and in some macrophages. The number of submucosal S100B-reactive dendritic cells was increased in bronchiolar walls, as expected in smokers. High levels of carboxy-methyl-lysine expression were present in alveolar macrophages, in bronchiolar epithelia, in reactive alveolar epithelia, and in extracellular fluids. Endothelia were frequently reactive for carboxy-methyl-lysine. 


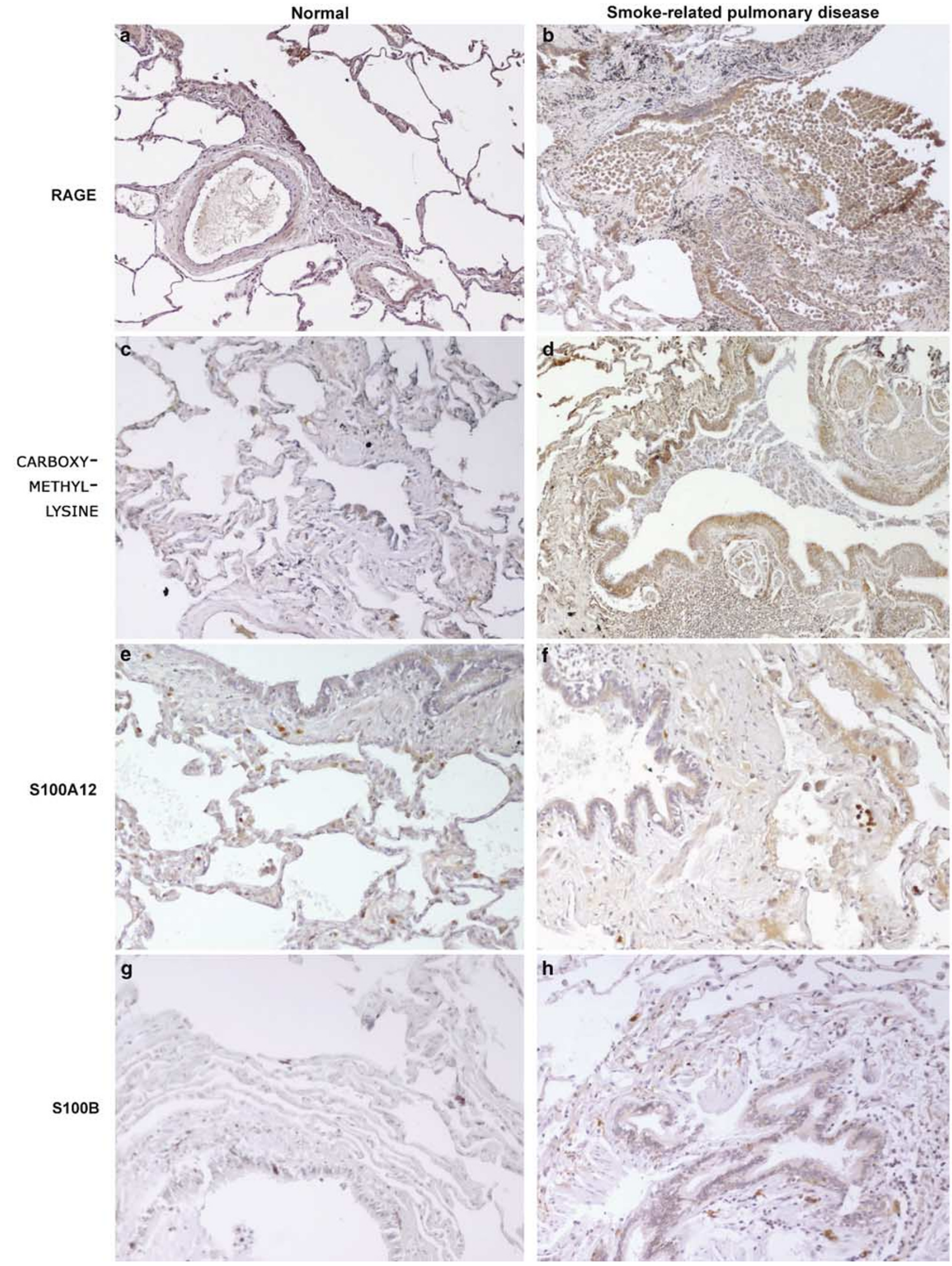


Nonspecific Inflammation Associated with Proximal Neoplastic Obstruction of Bronchus (Figure 3)

The presence of diffuse alveolar epithelial hyperplasia was associated with marked expression of RAGE in type II pneumocytes, which was highest in epithelia overlying lymphocytic nodular aggregates (Figure 2b). Endothelia, sparse fibroblasts and macrophages also expressed RAGE. The expression of S100B and S100A12 was increased in accordance with the increased number or polymorphonuclear and dendritic inflammatory cells; bronchiolar but not alveolar epithelia were faintly reactive for S100A12. Carboxy-methyl-lysine localization overlapped that of RAGE, being less intense in epithelial cells (Figure 2c). Where alveolar exudate was present, it showed reactivity for RAGE, carboxymethyl-lysine and S100A12.

\section{Organizing Pneumonia}

RAGE was present in hyperplastic alveolar epithelia, even those covering Masson bodies, and in bronchiolar epithelia; endothelia and macrophages were also highly immunoreactive. Some elongated cells of endoalveolar fibroblastic polyps expressed RAGE. Carboxy-methyl-lysine localization overlapped that of RAGE, with lower reactivity in epithelial cells. S100B and S100A12 were expressed respectively in dendritic and polymorphonuclear inflammatory cells; in half of the cases, hyperplastic type II pneumocytes and some alveolar macrophages also expressed a low degree of S100A12 reactivity. Where alveolar exudate was present, it showed reactivity for RAGE, carboxy-methyl-lysine and S100A12.

\section{Granulomatous Lung Disorders (Figure 3)}

Epithelioid and giant cells from sarcoid and tuberculous granulomas expressed RAGE at high levels; hyperplastic alveolar epithelia close to granulomas were also strongly immunoreactive. Histiocytes and giant cells of granulomas also expressed S100A12 and carboxy-methyl-lysine, and were infiltrated by S100B-reactive dendritic cells. Immunoreactivity of sarcoidosis samples for RAGE, S100A12, S100B and carboxy-methyl-lysine has been extensively investigated in a separate paper (Campo I et al, submitted $^{23}$ ). Cellular infiltrates of Langerhans cell histiocytosis were highly reactive for RAGE, S100B and carboxy-methyl-lysine but not for S100A12.

\section{Usual Interstitial Pneumonia (Figure 3)}

RAGE and carboxy-methyl-lysine were highly overexpressed in usual interstitial pneumonia, in reactive pneumocytes, bronchiolar metaplastic epithelium, and in endothelia. Carboxy-methyllysine, and, to a lesser extent, RAGE were present in the alveolar fluid. The number of infiltrating cells immunoreactive for S100B and S100A12 was variable from case to case. S100A12 reactivity was also present in reactive/hyperplastic pneumocytes, in part of alveolar macrophages, in some endothelia and in the alveolar fluid. Fibroblastic foci showed RAGE and carboxy-methyl-lysine reactivity both in the epithelial component and in the fibroblastic cells; epithelial cells also expressed S100A12 (Figure 4).

\section{Discussion}

The role of RAGE and its ligands in maintaining and amplifying inflammation has only recently been highlighted. RAGE-mediated tissue damage is being involved in chronic inflammatory pathology of multiple organs. ${ }^{5}$ The results of the present study suggest that the inflammatory pathway associated with RAGE-ligand binding could have a role also in chronic lung diseases. To date, RAGE had been identified in type II pneumocytes and macrophages from normal human lungs, ${ }^{17}$ and in type I pneumocytes of rat lung, where it was suggested as a marker of acute lung injury. ${ }^{24}$ Carboxy-methyl-lysine, the major component of AGEs, has been observed in bronchial epithelia and macrophages. ${ }^{25}$ Our study documented that low levels of RAGE are expressed in normal conditions in bronchial epithelia, type II pneumocytes, endothelia and macrophages, and that RAGE overexpression occurs in all pathological conditions associated with inflammation and lung damage. The increase in RAGE expression was not only due to the increased number of reactive pneumocytes and macrophages, which constitutively expressed RAGE in normal lungs, but also to the higher immunoreactivity observed in these cells with respect to normal conditions. In particular, RAGE was expressed at highest rate in pneumocytes and airway epithelia associated with inflammatory

Figure 1 RAGE and RAGE ligands expression in nonsmoker and smoker small airways. (a) In normal lung, bronchiolar epithelia are weakly stained with RAGE, as well as some endoalveolar macrophages. (b) Smoker airways show extensive RAGE reactivity in ciliated epithelia, endoluminal macrophages and in metaplastic alveolar cells surrounding the airways. (c) Extremely weak carboxy-methyllysine reactivity is observed in nonsmoker bronchiolar cells, while endovascular serum is shown to contain carboxy-methyl-lysine. (d) In smoker airways, the reactivity for carboxy-methyl-lysine overlaps that of RAGE. (e, f): S100A12 is present in interstitial and endovascular polymorphonuclear granulocytes in both conditions, as well as in endoalveolar exudates. Weak epithelial reactivity is considered nospecific. (g, h) S100B is exclusively expressed in submucosal and interstitial Langerhans cells, whose number is increased in smokers. (a-h) Immunoperoxidase stain, hematoxylin counterstain; (a-f, h) $\times 10$; (g) $\times 20$. 

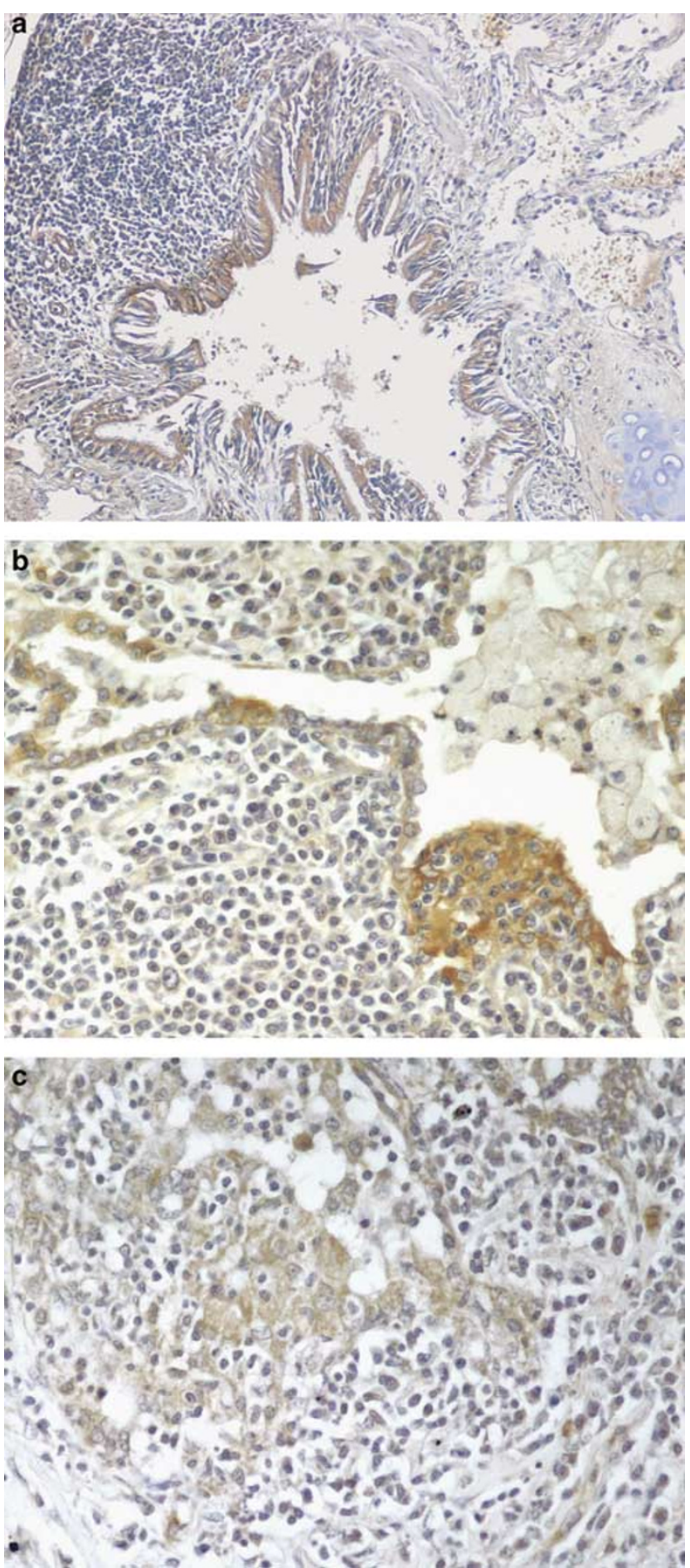

Figure 2 RAGE and AGE expression in inflamed lung. (a) Brochiolar epithelia in smoker airways and (b), alveolar pneumocytes, directly overlying lymphoid aggregates in postobstructive pneumonia are strongly immunoreactive for RAGE; (c) carboxymethyl-lysine is only weakly expressed in the same cells. (a-c) Immunoperoxidase stain, hematoxylin counterstain; (a) $\times 10$; $(\mathbf{b}, \mathbf{c}) \times 20$.

infiltrates. Moreover, we observed consistent RAGE expression in inflammatory cells, in particular in granulomas. ${ }^{23}$ As far as ligands are concerned, RAGE and AGE reactivity were similar in distribution and intensity, while the number of S100A12 and S100B immunoreactive inflammatory cells was highly variable. S100B reactivity was restricted to normal and pathologic dendritic cells; S100A12 was not only expressed in polymorphonuclear granulocytes and in cells of monocytic lineage (epithelioid and giant cells of granulomas) but also in activated epithelial cells. RAGE, S100A12 and carboxymethyl-lysine were also present in the serum and in endoalveolar fluid in inflammation.

A recent paper documented the presence of AGEs in macrophages and hyperplastic epithelia of lungs with usual interstitial pneumonia, but not of normal controls. The authors suggested that AGE-mediated activation of macrophages through binding with specific receptors could have a role in the fibrogenic process, since macrophages were stimulated to produce several cytokines and growth factors, such as TNF, IL-1, and PDGF, and mediators of oxidative stress. $^{26}$ Our study confirmed this observation, documenting that AGE and RAGE are coexpressed not only in inflammatory cells but also in reactive epithelial cells and fibroblasts in usual interstitial pneumonia and in several inflammatory and fibrosing pulmonary conditions, and that RAGE ligands of the S100-calgranulin family are synchronously present in different inflammatory cell populations. The production of AGE-modified proteins as a consequence of the oxidative stress associated both with pulmonary inflammation and with usual interstitial pneumonia ${ }^{21,22,27,28}$ and their binding with RAGE on different cell types can be considered as a possible, as yet not investigated, mechanism of cellular activation that leads to pulmonary tissue damage and fibrosis. In accordance with this hypothesis, Nf$\mathrm{kB}$, one downstream product of RAGE-mediated cellular activation, has been shown to have a specific binding site on the promoter of TGF- $\beta 1,{ }^{29}$ which is considered one of the key mediators in pulmonary fibrosis. ${ }^{30}$ Moreover, most of the cytokines induced by RAGE cellular activation have a profibrotic role in the lung. ${ }^{31}$

We also observed that, in normal lung, RAGE and carboxy-methyl-lysine were expressed in ciliated bronchial and bronchiolar epithelia. The number of RAGE and carboxy-methyl-lysine reactive cells and the intensity of expression were markedly increased in the lung of smokers both in epithelial and inflammatory cells. As smoke is associated with oxidative damage in the airway cells, ${ }^{18,19}$ it is possible that oxidative damage in bronchial/olar epithelia drives the production of AGE-modified proteins with subsequent activation of RAGE in epithelial and inflammatory cells, and RAGEmediated sustained inflammation and cytokine production. Interestingly, incubation with nornicotine has recently been shown to induce RAGE upregulation in human gingival fibroblasts, involving RAGE in smoke-related periodontal disease. ${ }^{32}$ Further studies are needed to clarify the association of RAGE with smoking and airway damage. 

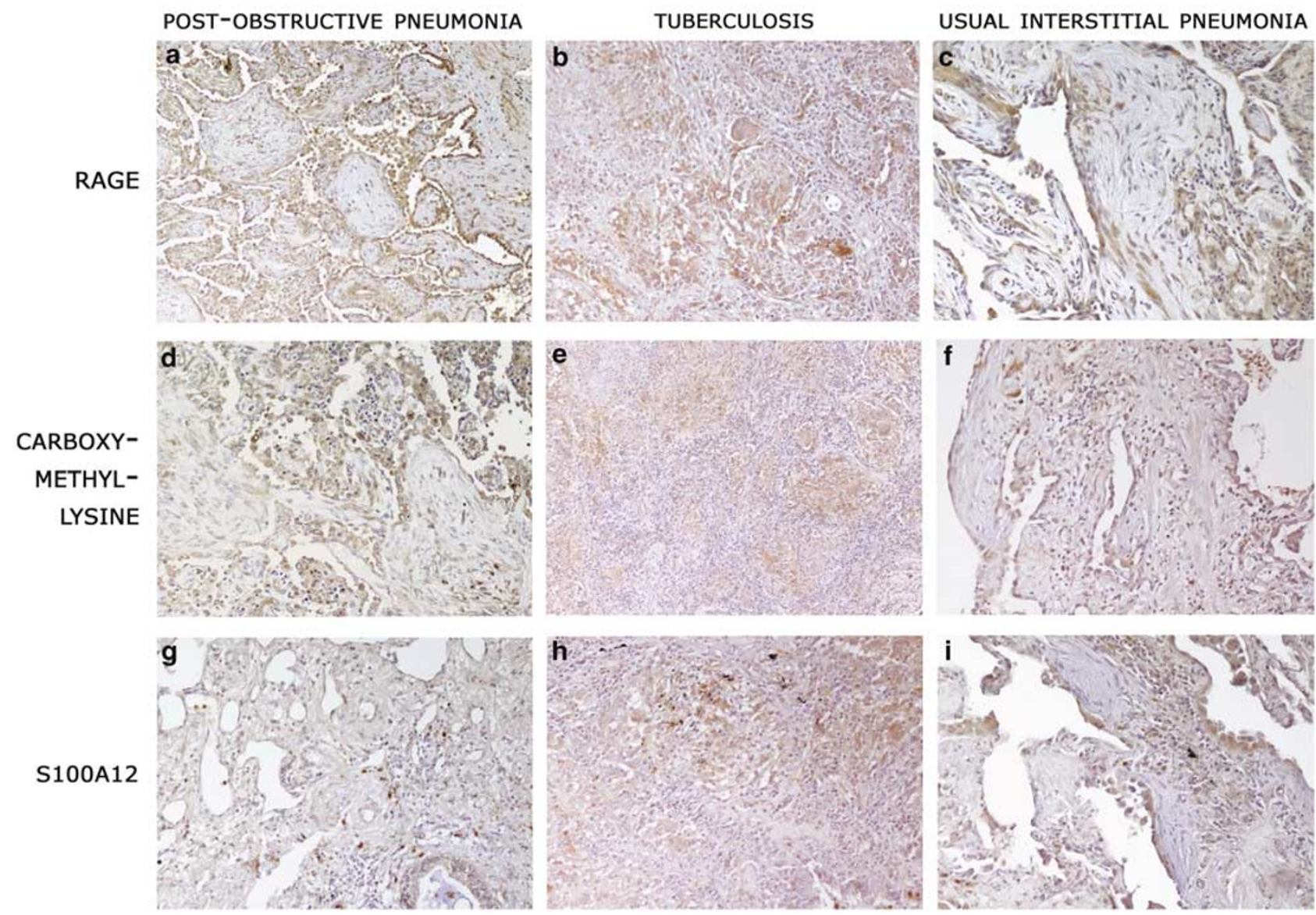

Figure 3 RAGE and RAGE ligand expression in nonspecific parenchymal inflammation and organization distal to neoplastic airway obstruction (postobstructive pneumonia), necrotizing granulomatous disease associated with mycobacterium tuberculosis infection, and in fibrotic lung disease with usual interstitial pneumonia pattern. In nonspecific parenchymal damage (a) RAGE and (d) carboxy-methyllysine are expressed in reactive type II pneumocytes and in inflammatory cells; (g) only scattered polymorphonuclear granulocytes express S100A12. In infective granulomas, epithelioid histiocytes and giant cells are reactive for (b) RAGE, (e) carboxy-methyl-lysine and (h) S100A12 (these cells do not express S100B data no shown). In usual interstitial pneumonia both hyperplastic epithelial and interstitial cells express (c) RAGE, (f) carboxy-methyl-lysine and (i) S100A12 (S100B is not expressed in the same cells, data no shown). (a-i) Immunoperoxidase stain, hematoxylin counterstain; (a, b, d-i) $\times 10$; (c) $\times 20$.

sRAGE is a secreted form of the receptor produced by alternative splicing of RAGE mRNA and is present in serum and alveolar exudate. ${ }^{33}$ The exogenous administration of this last splice variant has been demonstrated in experimental settings to have a negative role on RAGE-mediated proinflammatory action, since it prevents RAGE ligands from binding with the active, membrane-bound, receptor. $^{34}$ Controversial data exist on the relative distribution of different RAGE isoforms in normal tissues: a recent report has shown that sRAGE is the prevalent form expressed intracellularly in normal human tissues, ${ }^{17}$ suggesting that it may have other roles than binding AGEs. ${ }^{17}$ However, in the lung the occurrence of the full-length membranebound receptor has been documented both with immunohistochemistry and RT-PCR. ${ }^{17,33}$ As the antibody used for RAGE investigation binds with the extracellular V-type domain of the protein, which is present on both the full-length trans- membrane receptor and on the C-terminally truncated secretory forms we were unable to discriminate the active form of the transmembrane receptor from the secretory forms stored in the cytoplasm. However, the limited expression of RAGE in normal pulmonary tissue, the concomitant marked increase of RAGE and RAGE ligands expression in a wide range of full-blown inflammatory conditions, and the recent observation of full length and sRAGE, respectively, in alveolar epithelia and alveolar fluid in a rat model of diffuse alveolar damage ${ }^{24}$ suggest that most intracellular RAGE is the full-length isoform.

The observed highest expression of RAGE in alveolar and bronchiolar epithelia associated with inflammatory infiltrates is particularly interesting and is in accordance with the previous hypothesis that RAGE and its ligands may contribute to cell to cell binding and activation, similarly to the interaction of costimulatory molecules B7-1/B7-2 with 

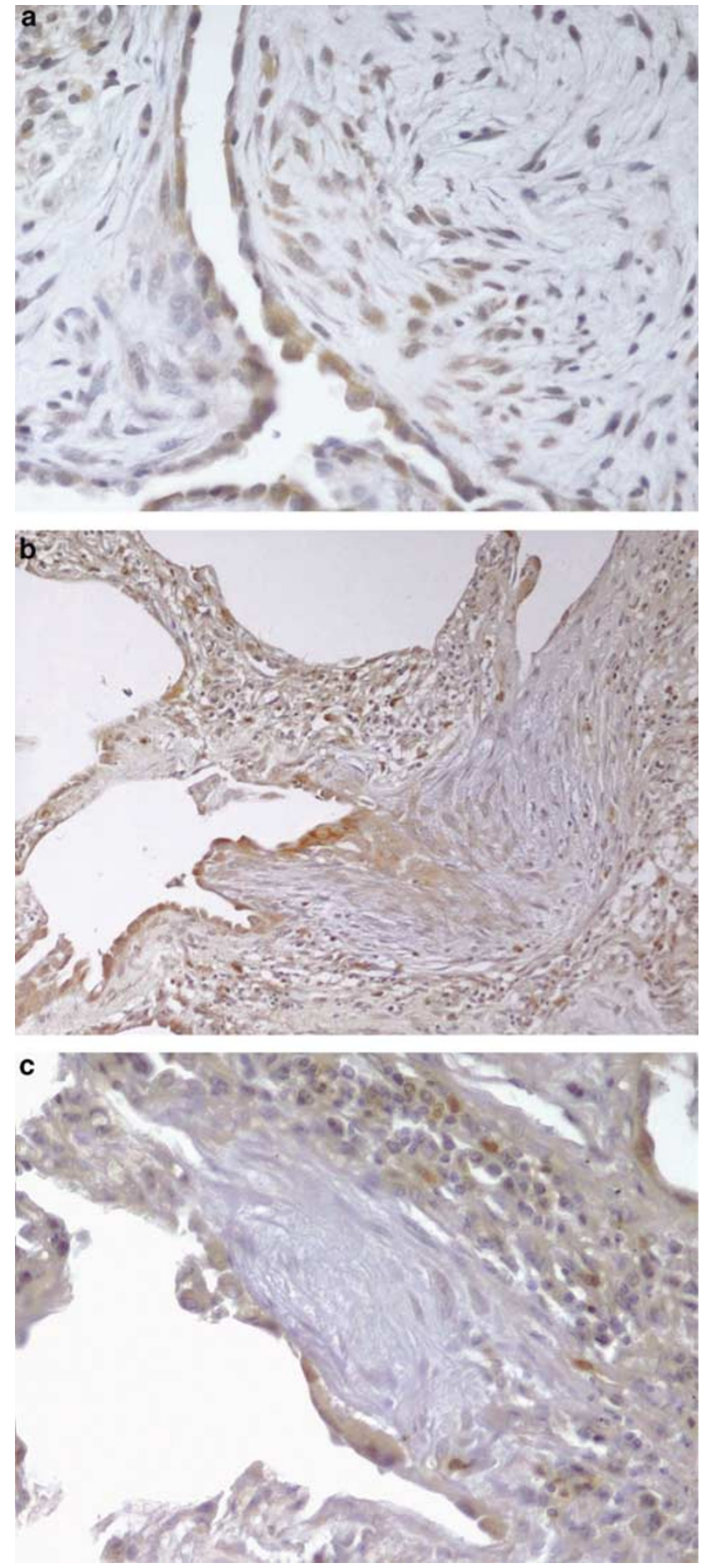

Figure 4 RAGE and RAGE ligand expression in fibroblastic foci of usual interstitial pneumonia. Reactive pneumocytes overlying fibroblastic foci of usual interstitial pneumonia and fibroblasts within the foci express (a) RAGE and (b) carboxy-methyl-lysine. Only epithelial and inflammatory cells (c) express S100A12. (a-c) Immunoperoxidase stain, hematoxylin counterstain; $(\mathbf{a}, \mathbf{c}) \times 40$; (b) $\times 20$.

CD28. ${ }^{1}$ The coexpression of carboxy-methyl-lysine in the same cells suggests that in this setting RAGEmediated cellular activation might have a role in the

formation of lymphoid aggregates, which have been associated with smoke-related airway obstruction. ${ }^{35}$

All data collected so far in different organ systems and pathological settings point toward a role of RAGE not as a causative or initiating factor for diseases, but rather as a mediator of amplification of chronic cellular activation and dysfunction. ${ }^{1}$ Consensus exists that ligand-RAGE interaction sustains the host response eventuating in chronic injury. The present study has contributed to extend the spectrum of RAGE-mediated diseases to lung inflammation and damage. The activation of RAGE inflammatory pathway is by no means specific of a single lung disease, since is has been observed in conditions ranging from smoke-induced bronchial damage to granulomatous disorders, to idiopathic pulmonary fibrosis. However, RAGE activation may be relevant as a nonspecific pathway of sustained inflammation in lung tissue, and on this basis therapeutic approaches based on RAGE blockage can be envisaged.

\section{References}

1 Schmidt AM, Yan SD, Yan SF, et al. The multiligand receptor RAGE as a progression factor amplifying immune and inflammatory responses. J Clin Invest 2001;108:949-955.

2 Yan SF, Ramasamy R, Naka Y, et al. Glycation, inflammation, and RAGE: a scaffold for the macrovascular complications of diabetes and beyond. Circ Res 2003;93:1159-1169.

3 Ritthaler U, Deng Y, Zhang Y, et al. Expression of receptors for advanced glycation end products in peripheral occlusive vascular disease. Am J Pathol 1995;146:688-694.

4 Cipollone F, Iezzi A, Fazia M, et al. The receptor RAGE as a progression factor amplifying arachidonate-dependent inflammatory and proteolytic response in human atherosclerotic plaques: role of glycemic control. Circulation 2003;108:1070-1077.

5 Hofmann MA, Drury S, Fu C, et al. RAGE mediates a novel proinflammatory axis: a central cell surface receptor for S100/calgranulin polypeptides. Cell 1999; 97:889-901.

6 Hofmann MA, Drury S, Hudson BI, et al. RAGE and arthritis: the G82S polymorphism amplifies the inflammatory response. Genes Immun 2002;3:123-135.

7 Brownlee M. The pathological implications of protein glycation. Clin Invest Med 1995;18:275-281.

8 Donato R. Intracellular and extracellular roles of S100 proteins. Microsc Res Tech 2003;60:540-551.

9 Foell D, Kane D, Bresnihan B, et al. Expression of the pro-inflammatory protein S100A12 (EN-RAGE) in rheumatoid and psoriatic arthritis. Rheumatology 2003;42:1383-1389.

10 Foell D, Seeliger S, Vogl T, et al. Expression of S100A12 (EN-RAGE) in cystic fibrosis. Thorax 2003; 58:613-617.

11 Foell D, Kucharzik T, Kraft M, et al. Neutrophil derived human S100A12 (EN-RAGE) is strongly expressed during chronic active inflammatory bowel disease. Gut 2003;52:847-853. 
12 Neeper M, Schmidt AM, Brett J, et al. Cloning and expression of a cell surface receptor for advanced glycosylation end products of proteins. J Biol Chem 1992;267:14998-15004.

13 Schmidt AM, Vianna M, Gerlach M, et al. Isolation and characterization of two binding proteins for advanced glycosylation end products from bovine lung which are present on the endothelial cell surface. J Biol Chem 1992;267:14987-14989.

14 Brett J, Schmidt AM, Yan SD, et al. Survey of the distribution of a newly characterized receptor for advanced glycation end products in tissues. Am J Pathol 1993;143:1699-1712.

15 Katsuoka F, Kawakami Y, Arai T, et al. Type II alveolar epithelial cells in lung express receptor for advanced glycation end products (RAGE) gene. Biochem Biophys Res Commun 1997;238:512-516.

16 Shirasawa M, Fujiwara N, Hirabayashi S, et al. Receptor for advanced glycation end-products is a marker of type I lung alveolar cells. Genes Cells 2004;9:165-174.

17 Cheng C, Tsuneyama K, Kominami R, et al. Expression profiling of endogenous secretory receptor for advanced glycation end products in human organs. Mod Pathol 2005;18:1385-1396.

18 Kinnula VL. Focus on antioxidant enzymes and antioxidant strategies in smoking related airway diseases. Thorax 2005;60:693-700.

19 Seagrave J. Oxidative mechanisms in tobacco smokeinduced emphysema. J Toxicol Environ Health A 2000;61:69-78.

20 Kinnula VL. Production and degradation of oxygen metabolites during inflammatory states in the human lung. Curr Drug Targets Inflamm Allergy 2005;4:465-470.

21 Kinnula VL, Fattman CL, Tan RJ, et al. Oxidative stress in pulmonary fibrosis: a possible role for redox modulatory therapy. Am J Respir Crit Care Med 2005; 172:417-422.

22 American Thoracic Society; European Respiratory Society. American Thoracic Society/European Respiratory Society International Multidisciplinary Consensus Classification of the Idiopathic Interstitial Pneumonias. This joint statement of the American Thoracic Society (ATS), and the European Respiratory Society (ERS) was adopted by the ATS board of directors, June 2001 and by the ERS Executive Committee, June 2001. Am J Respir Crit Care Med 2002;165:277-304.

23 Campo I, Morbini P, Zorzetto M, et al. Expression of receptor for advanced glycation end-products in sarcoid granulomas. Submitted.
24 Uchida T, Shirasawa M, Ware LB, et al. Receptor for advanced glycation end-products is a marker of type I cell injury in acute lung injury. Am J Respir Crit Care Med 2006 (E-pub ahead of print).

25 Ling X, Sakashita N, Takeya M, et al. Immunohistochemical distribution and subcellular localization of three distinct specific molecular structures of advanced glycation end products in human tissues. Lab Invest 1998;78:1591-1606.

26 Matsuse T, Ohga E, Teramoto S, et al. Immunohistochemical localisation of advanced glycation end products in pulmonary fibrosis. J Clin Pathol 1998; 51:515-519.

27 Lakari E, Soini Y, Saily $\mathrm{M}$, et al. Inducible nitric oxide synthase, but not xanthine oxidase, is highly expressed in interstitial pneumonias and granulomatous diseases of human lung. Am J Clin Pathol 2002; 117:132-142.

28 Kuwano K, Nakashima N, Inoshima I, et al. Oxidative stress in lung epithelial cells from patients with idiopathic interstitial pneumonias. Eur Respir J 2003; 21:232-240.

29 Lee KY, Ito K, Hayashi R, et al. NF-\{kappa\}B and activator protein 1 response elements and the role of histone modifications in IL-1\{beta\}-Induced TGF-\{beta\}1 gene transcription. J Immunol 2006;176:603-615.

30 Chapman HA. Disorders of lung matrix remodeling. J Clin Invest 2004;113:148-157.

31 Antoniou KM, Alexandrakis MG, Siafakas NM, et al. Cytokine network in the pathogenesis of idiopathic pulmonary fibrosis. Sarcoidosis Vasc Diffuse Lung Dis 2005;22:91-104.

32 Katz J, Caudle RM, Bhattacharyya I, et al. Receptor for advanced glycation end product (RAGE) upregulation in human gingival fibroblasts incubated with nornicotine. J Periodontol 2005;76:1171-1174

33 Schlueter C, Hauke S, Flohr AM, et al. Tissue-specific expression patterns of the RAGE receptor and its soluble forms-a result of regulated alternative splicing? Biochim Biophys Acta 2003;1630:1-6.

34 Yonekura H, Yamamoto Y, Sakurai S, et al. Novel splice variants of the receptor for advanced glycation end-products expressed in human vascular endothelial cells and pericytes, and their putative roles in diabetes-induced vascular injury. Biochem J 2003;370 1097-1109.

35 Hogg CJ, Chu F, Utokaparch S, et al. The nature of small-airway obstruction in chronic obstructive pulmonary disease. N Engl J Med 2004;350:2645-2653. 